\title{
New Age Youth Helps Rural Rejuvenation Strategy
}

\author{
Du Piao-piao, * \\ ${ }^{1}$ China West Normal University, Nanchong, Sichuan Province, 637002, China \\ "Corresponding author. Email: 250434861@qq.com
}

\begin{abstract}
Keywords: Youth, rural revitalization

\section{INTRODUCTION}

To implement the strategy of rural revitalization, young students in the new era must also be obliged to shoulder their responsibilities, use their knowledge to realize their dreams, and display their talents. The vitality of rural revitalization depends on talents. General Secretary Xi Jinping emphasized that college students are also making contributions to the grassroots and rural areas if they are not afraid of hardship. Aspiring young people should take advantage of the trend and make a difference, conserve the seeds of dreams in the rural soil, and create unlimited possibilities on the stage of the times. Only in this way can I live up to the most beautiful youth.
\end{abstract}

The report of the Nineteenth National Congress of the Communist Party of China made major decisionmaking arrangements for the implementation of the strategy of rural revitalization. 2020 is the year of the finalization of the nation's decisive battle against poverty, and it is also a crucial year. As of this year, there are still 52 poverty-stricken counties, so our young students must make a difference, fight for poverty alleviation in China and build a well-off society in an all-round way to exert their own strength.

\subsection{The Young People's Initiative to Return Home is not High}

Young people are the future and hope of the motherland, a solid reserve force for the realization of the Chinese dream, and the backbone of the Chinese nation. To realize the revitalization of the countryside, the problem of talents must be solved. The majority of contemporary young students do not understand or fully understand the countryside, farmers, and agriculture. Most of the impressions of the countryside are backward facilities, poor basic conditions, and dirty and messy living conditions. There is no basic life guarantee for young talents to return to their hometowns for entrepreneurship. In addition, there are no hardware and software facilities suitable for the life, socialization and learning of young talents in rural areas.

First, rural youths are influenced by their parents and society, and they are eager to stay in the city to work and live in the city, and enjoy the rich medical and educational resources in the city. Received a strange vision.

Second, urban youth have no sense of belonging in the countryside. Due to the development of urban industrialization, most young and middle-aged people in rural areas choose to go out to work. Many villages have only young children and old people left behind, and even many remote mountainous areas have various natural disasters and environmental problems. Urban youth cannot adapt to local life after returning to their hometowns. Then choose to return to the city.

It can be seen from this that the vast numbers of young talents are not highly motivated to return to their hometowns, the villages are not attractive to the broad masses of young people, and they cannot retain young talents.

\subsection{The Public Opinion Guidance of the Society and the Media is not Timely}

\footnotetext{
Nowadays, the strategy for the revitalization of the countryside by the vast number of young people is inseparable from the guidance of society and the media. Social media are currently the main channel for people to obtain information, which can affect the recognition and attention of the youth on the rural revitalization strategy. Therefore, to unite the strength of youth to promote rural revitalization, it is necessary to strengthen the guidance of public opinion in the society and the media, and actively promote the participation of Chinese youth in the rural revitalization strategy.

The author has adopted two methods of Baidu index search and HowNet retrieval. First, as of March 2020, the Baidu index search for "village revitalization" and the attributes of people who are concerned about "village revitalization" are: less than 19 years old account for $14.03 \%$, 20-29 years old accounted for 13\%, 30-39 years old accounted for $24.7 \%, 40-49$ years old accounted for $4.31 \%$, more than 50 years old accounted for $0.66 \%$. Second, as of March 2020, China HowNet has searched for two keywords, "youth" and "rural revitalization", and 96 related articles [1].

It can be seen that the social and media attention to the youth participation in rural revitalization is insufficient. Many young people will not pay attention to rural revitalization on the Internet. Young students do not have enough knowledge about the rural revitalization strategy. Most students will not choose after graduation Return home to develop.
} 


\subsection{The Supporting Policies of Local Governments Are Incomplete}

Some scholars found in the questionnaire that insufficient government policy support is the main factor that restricts youth's inactivity in participating in rural revitalization. Although the party and government have introduced policies to encourage young talents to build rural areas, such as "three support and one support", some young people use this as a springboard for their own promotion, and then use various ways to leave the countryside [2]. The majority of young people return to their hometowns to start a business and have problems of being unaffordable and unavailable. Most young people do not have suitable positions for working in rural areas due to professional problems, and have low income and narrow promotion channels. There is more than enough. On the other hand, due to the lack of overall competitiveness of the agricultural industry and the lack of resources and funds, local government policy support is insufficient, which also makes it difficult for young talents to return to their hometowns and start businesses.

\section{BACKGROUND GATHERING STRENGTH OF YOUTH TO HELP RURAL REVITALIZATION}

\subsection{Strengthen Learning and Improve Professional Quality}

Contemporary youths are the main force for the realization of China 's socialist modernization and the revitalization of the countryside. They are the source of strength for the prosperity of the country and the prosperity of the people. The broad masses of young people must strengthen their professional qualities, improve their personal professional abilities, further strengthen their ideals and beliefs in their studies and thinking, and help revitalize the countryside. General Secretary Xi Jinping said in his May 9th speech: Learning is for the unity of knowledge and action, and it is used in the world. As a contemporary young college student, we must pay attention to strengthening our own learning, apply what we learn, and live up to General Secretary Xi Jinping's deep expectations for our young students. Rural revitalization is for both people and people. Therefore, the majority of young people must have excellent professional qualities in rural revitalization in order to better commit themselves to rural revitalization. In this way, after returning to their hometowns, the majority of young people can contribute their strength to the rural revitalization of the motherland, no matter whether it is "main specialty" or "interdisciplinary".

\subsection{Rooted at the Grassroots Level and Devoted to Rural Revitalization and Construction}

Taking root at the grassroots level, the first thing is not to forget the original intention. When young people take root at the grassroots level, it is often difficult to gain the trust and recognition of villagers and village cadres, and most young people do not understand the local village and people's feelings, and are prone to frustration in their work. Some scholars believe that factors such as the crisis of trust will bring various challenges to youth's social integration, further restricting youth's participation in rural grassroots governance and rural revitalization.[3] Therefore, when young people take root at the grassroots level, they must not forget their original intentions, and learn from the grassroots staff to work at the grassroots level, such as adjusting the relationship between the villagers and handling conflicts with the villagers. It is impossible to integrate into the grassroots work.

Second, keep learning. Some scholars have studied the current situation of the first secretary after entering the office, and found that the young first secretary generally exists after entry: they are not qualified for their current positions, the work has not entered a benign state of operation or is in a state of stagnation; management is chaotic, lack of democratic management mechanisms, and village affairs management is chaotic; Contradictions in letters and visits are prominent.[4]Learning is a lifelong process, whether it is for theoretical knowledge or professional ability. Young people must learn theoretical knowledge in a timely manner in the work of revitalizing the grassroots in rural areas, and apply theoretical knowledge to their work. One of the main problems of agriculture, rural areas and farmers is information blocking. When young people are devoted to rural primary work, learning can not only enrich their own qualities and standards, but also pass on the new policies of the party and the state to villagers in a timely manner. To swell up, we must first enrich the peasants' minds, and promote the revitalization of the countryside in the same direction of national and local policies.

Finally, young people must persevere. The concrete actions of contemporary youth to participate in rural revitalization are not only the result of rational choices in the market, but also full of the simple emotions of cultural nostalgia and the ideal ambition of social responsibility. However, due to the influence of systems, policies, systems and incentive mechanisms, social care, etc., the enthusiasm of young people for the revitalization of rural areas has gradually declined. [5] The broad masses of young people who have taken root at the grassroots must maintain their perseverance and devote themselves to the revitalization of the countryside. They cannot be heated for three minutes, nor can they be abandoned halfway. Most young people know nothing about the countryside, and even the crops are unclear. Many young people gave up because they could not endure hardship after they voted for rural revitalization. Therefore, devotion to rural 
revitalization cannot be impulsive for a while, and it requires the perseverance and perseverance of the broad masses of young people.

General Secretary Xi Jinping pointed out that college students can also realize their own life value when they go to the grassroots. When young people are involved in the revitalization of the countryside, they must take root at the grassroots level, stand in the perspective of the villagers, think about what the people think, and worry about the needs of the people. Rejuvenation and construction, leading more young students in the new era who know the countryside and love the countryside, and devote themselves to the upsurge of rural revitalization.

\subsection{Scientific Planning to Help Rural Revitalization}

\subsubsection{According to the village conditions, local policies}

Rural revitalization not only refers to economic development, but also includes political, environmental, and cultural construction. Therefore, we must promote rural revitalization according to local conditions and continue to meet the material and spiritual cultural needs of villagers. First of all, according to the different village conditions, different development plans are formulated. China has a large population and a vast area. The agricultural development, rural population structure and farmers' living habits in different places are very different. Therefore, in different rural areas, it is necessary to take measures according to local conditions. When young people are helping the revitalization of the countryside, they must not engage in flower racks. They must go deep into the masses, understand the real needs of farmers, and strive to become new youths who love farmers and love the countryside. Develop plan goals that really benefit farmers. For example: improving rural drinking water, improving rural dilapidated houses, making land adjustment planning, regulating rural waste discharge, etc. Secondly, at the same time, moral education and practical knowledge training for villagers should be carried out; finally, the promotion of rural civilization, civilized life, civilized labor, civilized language, etc., and the standardization of villagers 'daily life and bad habits in production, such as civilization The establishment of red and white happy events, etc., improves the farmers' quality of life and happiness index from all aspects [6].

\subsubsection{Go to the countryside and do your best}

The main position for rural revitalization is in rural areas, so to achieve rural revitalization, young talents who love the countryside and farmers must actively go to the countryside for entrepreneurial development. Young people who are involved in agriculture must give full play to their professional abilities when they help rural revitalization work, combine with the development of the rural economy, and give full play to their advantages to contribute to rural revitalization. "Cross-professional" young talents need adequate preparation, systematic study of technology and experience, etc. to understand the support policies of the national and local governments when they choose to start a business in an unfamiliar industry. The risk of failure is reduced to less. For the youth to implement rural revitalization, they must first adhere to the villagers as the center and focus on economic development and villagers' lives; secondly, they need to gather their strengths to go to the countryside and do their best to build a rich and civilized new village for the villagers; and finally Adhere to the party's leadership, serve the people wholeheartedly, commit to the development of the villagers' ecology, economy, and civilization, and make the villagers more support the party's leadership.

\subsubsection{Gather multiple forces to help together}

When young people are engaged in the work of rural revitalization, they cannot rely on the strength of one person. They must unite various forces to jointly carry out rural revitalization. On the one hand, it is to unite the internal forces of youth. One person is short and the other two are long, bringing together young people of different professions to jointly promote the rural revitalization work. For example, college party and league organizations can organize students of different majors and different living areas to carry out special activities of social practice in summer vacation. Students of liberal arts departments can carry out law popularization education and civilized and standardized education for villagers; students of the Academy of Agricultural Sciences can work together with villagers Popularization of new agricultural science and technology; other departments can carry out corresponding poverty alleviation work according to the characteristics of the discipline. Youth should also properly combine external forces. For example, young students can experience the situation of rural revitalization and poverty alleviation through their own experience, write a survey report, and report it to schools and relevant departments from the perspective of youth. Young students of journalism departments can take up their hands the camera's lens records what it looks like, makes a video for publicity, expands the visibility of the village, and taps the diversification of the rural economic and industrial structure.

\section{CONCLUSION}

Rural revitalization requires young people who understand the countryside, have culture, are capable, and have feelings for the countryside. With the continuous development of the rural revitalization work, there are 
many difficulties and challenges that we are currently facing, but contemporary youth must not forget their original intentions and keep in mind the mission, actively participate in the construction of rural revitalization in our country, and use practical actions to help rural revitalization, so that the youth's own value lies in Rural revitalization has been achieved, rooted in rural revitalization, grassroots work, within our dedication to dedicate youth to the construction of socialist modernization, with dreams as a horse to live up to youth.

\section{REFERENCES}

[1] Z.Y. Xiao, Y.H. Chen, R.Q. Wu, "Absence" and "Return": Research on the Participation of Chinese Youth in Rural Revitalization in the New Era, "Youth Exploration", No.3, 2019.

[2] M. Luo, "From" Leaving Home "to" Returning Home ": Action Logic of Youth Participating in Rural Revitalization: Based on a Questionnaire Analysis of
1,231 Youths in Z City, Province H," China Youth Research ", No.9, 2019

[3] G.D. Zhang,"Grassroots Governance and Rural Revitalization: The Action Paradigm of the First Secretary of Youth", "Chinese Youth Research ", Issue 9, 2019.

[4] F. Yang, "First Secretary" in the Village and Village Governance Reform," Learning Forum", No.2, 2016.

[5] X.W. Hu, "Market rationality and cultural nostalgia: The Youth Mirror and Group Psychology in the Rural Revitalization Strategy", "Chinese Youth Research", Issue 9, 2019.

[6] Y.X. Hu, "Worry of Survival and Confusion of Development: The Role Reconstruction of Youth Village Cadres from the Perspective of Rural Revitalization", "Chinese Youth Research", Issue 9, 2019. 